\title{
FIRST ON-LINE RESULTS FOR AS AND F BEAMS FROM HRIBF TARGET / ION SOURCES
}

\author{
D. W. Stracener ${ }^{a}$, H. K. Carter ${ }^{b}$, J. Kormicki ${ }^{b, \dagger}$, \\ J. C. Blackmon', M. S. Smith ${ }^{\mathrm{d}}$ and D. W. Bardayan \\ a Joint Institute for Heavy Ion Research, Oak Ridge, TN 37831 \\ ${ }^{b}$ Oak Ridge Institute for Science and Education, Oak Ridge, TN 37831 \\ ' The University of North Carolina at Chapel Hill, Chapel Hill, NC 27599 \\ 'Oak Ridge National Laboratory, Oak Ridge, TN 37831 \\ `A. W. Wright Nuclear Structure Laboratory, Yale University, New Haven, CT 06511
}

\begin{abstract}
The first on-line tests of the ion sources to provide radioactive ion beams of ${ }^{69.70} \mathrm{As}$ and ${ }^{17,18} \mathrm{~F}$ for the Holifield Radioactive Ion Beam Facility (HRIBF) have been performed using the UNISOR facility at HRIBF. The target/ion source is an electron beam plasma (EBP) source similar to the ISOLDE design. The measured efficiencies for ${ }^{69} \mathrm{As}$ and ${ }^{70} \mathrm{As}$ were $0.5 \pm 0.2 \%$ and $0.8 \pm 0.3 \%$, respectively. The arsenic hold-up time in the tested target/ion source was $3.6 \pm 0.3$ hours as measured with ${ }^{72} \mathrm{As}$ at a target temperature of $1300^{\circ} \mathrm{C}$. The measured efficiencies for ${ }^{17} \mathrm{~F}$ and ${ }^{18} \mathrm{~F}$ were $0.0052 \pm 0.0008 \%$ and $0.06 \pm 0.02 \%$, respectively. The source hold-up time for fluorine was measured with $\mathrm{Al}^{18} \mathrm{~F}$ since $88 \%$ of the observed radioactive fluorine was found in this molecule. The $\mathrm{Al}^{18} \mathrm{~F}$ hold-up time was $16.4 \pm 0.8$ minutes at a target temperature of $1470^{\circ} \mathrm{C}$.
\end{abstract}

\section{INTRODUCTION}

The recently completed Holifield Radioactive Ion Beam Facility (HRIBF) is designed to provide energetic radioactive ion beams for nuclear physics and nuclear astrophysics research. To produce these beams, light ions from the $\mathrm{K}=100$ Oak Ridge Isochronous Cyclotron (ORIC) will impact a thick target in the ion source of an isotope separator. The extracted radioactive ions, after mass analysis and charge exchange, are injected into the $25 \mathrm{MV}$ tandem accelerator. One of the most challenging aspects of this project is the performance of the target/ion source of the isotope separator. This paper presents results of on-line tests of the initial version of the ion source used to produce arsenic beams. Also, preliminary results for fluorine beams from a similar source are described.

\section{EXPERIMENTAL RESULTS}

The UNISOR (1) separator on-line to the Holifield tandem accelerator provides a unique capability (2) to investigate target/ion source performance. Proton and deuteron beams of energy up to $40 \mathrm{MeV}$ are used to produce the desired radioisotopes directly in the target/ion source under investigation. The mass separated ions are counted using traditional on-line nuclear spectroscopy techniques with a moving tape system, $\gamma$-ray detector and spectrum multiscaling techniques. Alternatively, in experiments prior to those reported here, heavy ion implantation experiments similar to those of Kirchner (3) were used to measure release times and efficiencies of various beam/target combinations (2) in preparation for designing and constructing the target/ion source used here.

\section{Target/Ion Source}

The target/ion source used in these studies is a modified version of the general design (4) for the HRIBF facility which is similar to the CERN/ISOLDE design (5). Figure 1 shows the electron beam plasma ion source as used in these experiments. The following modifications were made specifically for a liquid germanium target which will be used to produce radioactive arsenic ion beams. Since the vapor pressure of germanium is $10^{-4}$ torr at $1100^{\circ} \mathrm{C}$, it was expected that this would be the maximum operating temperature for the target. With this in mind, the design of the target heater was simplified to a singlepass current path, with an attached heat shield. The cathode current connection was moved from midway along the cathode transfer tube to the rear-most point. This ensures that the transfer line will be at the highest possible temperature which will help to reduce the sticking time (6) of arsenic on the tantalum surfaces. Several layers of $0.025 \mathrm{~mm}$ thick tantalum around the transfer line provide additional heat shielding. A carbon target holder, with a $1 \mathrm{~mm}$ thick entrance window, is used since tantalum reacts strongly with germanium. The germanium target, designed to stop $40 \mathrm{MeV}$ protons is $4 \mathrm{~mm}$ thick by $9 \mathrm{~mm}$ diameter. 


\section{DISCLAIMER}

This report was prepared as an account of work sponsored by an agency of the United States Government. Neither the United States Government nor any agency thereof, nor any of their employees, makes any warranty, express or implied, or assumes any legal liability or responsibility for the accuracy, completeness, or usefulness of any information, apparatus, product, or process disclosed, or represents that its use would not infringe privately owned rights. Reference herein to any specific commercial product, process, or service by trade name, trademark, manufacturer, or otherwise does not necessarily constitute or imply its endorsement, recommendation, or favoring by the United States Government or any agency thereof. The views and opinions of authors expressed herein do not necessarily state or reflect those of the United States Government or any agency thereof. 


\section{DISCLAIMER}

Portions of this document may be illegible in electronic image products. Images are produced from the best available original document. 


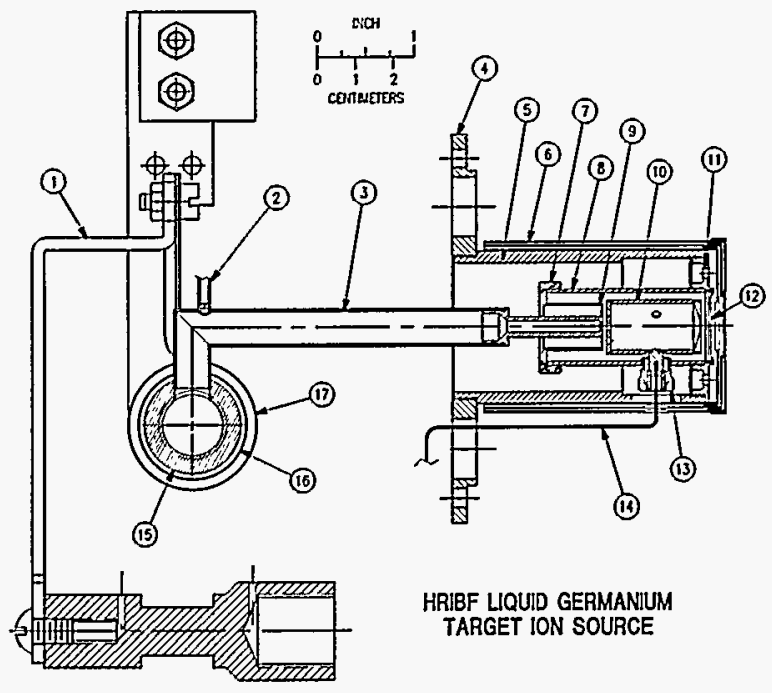

FIGURE 1. Axial cut of the HRIBF liquid germanium target/ion source. Part numbers and construction material are indicated: 1. cathode current lead $(\mathrm{Ta}), 2$. gas (Xe) transfer line $(\mathrm{Ta})$, 3. transfer line (Ta), 4. head flange (C), 5. outer tube (C), 6. heat shields (Mo or Ta), 7. cathode support nut (Mo), 8. anode support tube (Ta), 9. cathode (Ta), 10, anode tube (Ta), 11. end flange (Mo), 12. anode heat shields (Mo), 13. anode support assembly ( $\mathrm{Ta}, \mathrm{BeO}, \mathrm{Mo}), 14$. anode wire (Mo), 15, target holder ( $\mathrm{C}$ for $\mathrm{Ge}, \mathrm{Ta}$ for $\mathrm{Al}_{2} \mathrm{O}_{3}$ ), 16 . target heater $(\mathrm{Ta}), 17$, heater heat shield $(\mathrm{Ta})$.

Several copies of this target/ion source have been constructed and tested off-line to determine typical operating parameters. The single current pass target heater has operated reliably over a wide range of target temperatures starting at $900^{\circ} \mathrm{C}$, with no heater current, up to $1570^{\circ} \mathrm{C}$ with a heater current of $480 \mathrm{~A}$. Moving the cathode connection to the rear of the transfer tube enables the entire line to be operated at temperatures in excess of $1700^{\circ} \mathrm{C}$, as measured at the coldest point next to the cathode current connection, with a current of about $350 \mathrm{~A}$. The other operational parameter which is important for the germanium target is the target temperature without any heater current. This temperature is approximately $900^{\circ} \mathrm{C}$ with cathode and anode at operational conditions. Typical ion source efficiency for Xe is $10-15 \%$ with the cathode current of $350 \mathrm{~A}$ and anode current of $200 \mathrm{~mA}$ at 150 volts. For on-line experiments the Xe gas inlet is restricted to 0.3 $\mathrm{mm}$ in order to reduce the flow of reaction products into the gas line. With this arrangement the on-line $\mathrm{Xe}$ efficiency is reduced to $3 \%$.

\section{On-Line Arsenic Experiments}

The performance of the ion source for the production of arsenic beams was tested using $(p, n)$ and $(p, 2 n)$ reactions on a natural $99.999 \%$ pure germanium target mounted in the ion source. The extracted arsenic ions were deposited onto the tape transport system for 10 minutes and then moved to the detector station and the activity of the sample was counted for 8 minutes. The count rates shown in Fig. 2 are net counts in the

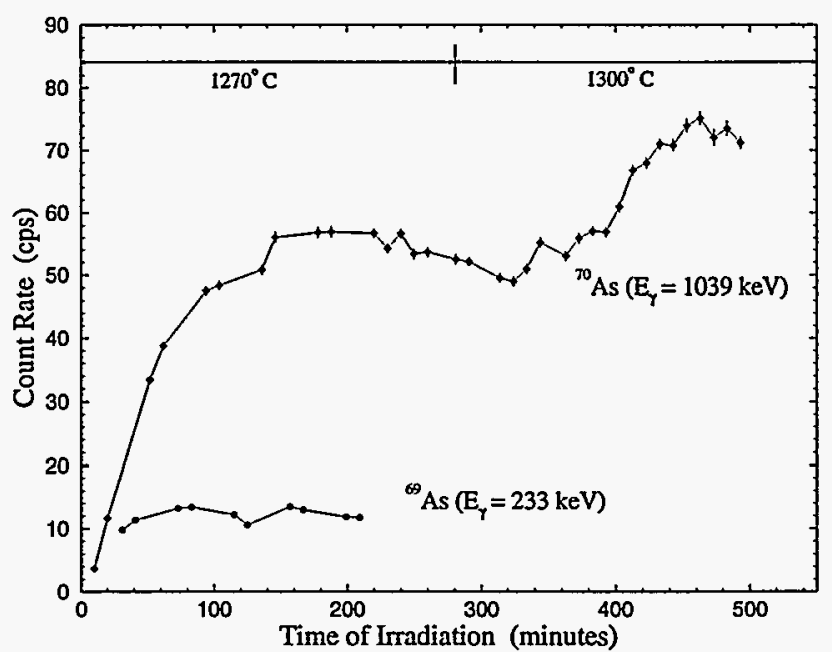

FIGURE 2. Release of ${ }^{69} \mathrm{As}$ and ${ }^{70} \mathrm{As}$. The net count rate of a characteristic $\gamma$-ray from each isotope is plotted. No corrections for detector efficiency or branching ratios have been made. These data were taken at the two indicated target temperatures.

respective transitions. The data are used to determine the absolute efficiency for the target/ion source. These data also clearly show a hold-up time in the target/ion source and an improvement in yield as the target temperature is increased. Using these yield curves and calculated production rates (7), the efficiency of the target/ion source at $1270^{\circ} \mathrm{C}$ was $0.8 \pm 0.3 \%$ for ${ }^{70} \mathrm{As}$ and $0.5 \pm 0.2 \%$ for ${ }^{69} \mathrm{As}$.

Since the growth curves seem to be dominated by the half-life of the respective isotopes, the hold-up time as implied from Fig. 2 must be longer than the half-life of either ${ }^{69} \mathrm{As}$ or ${ }^{70} \mathrm{As}$. In order to measure the hold-up time in the target/ion source it was necessary to use an arsenic isotope with a longer half-life. After proton irradiation for several hours enough ${ }^{72} \mathrm{As}\left(\mathrm{t}_{1}=26.0 \mathrm{~h}\right)$

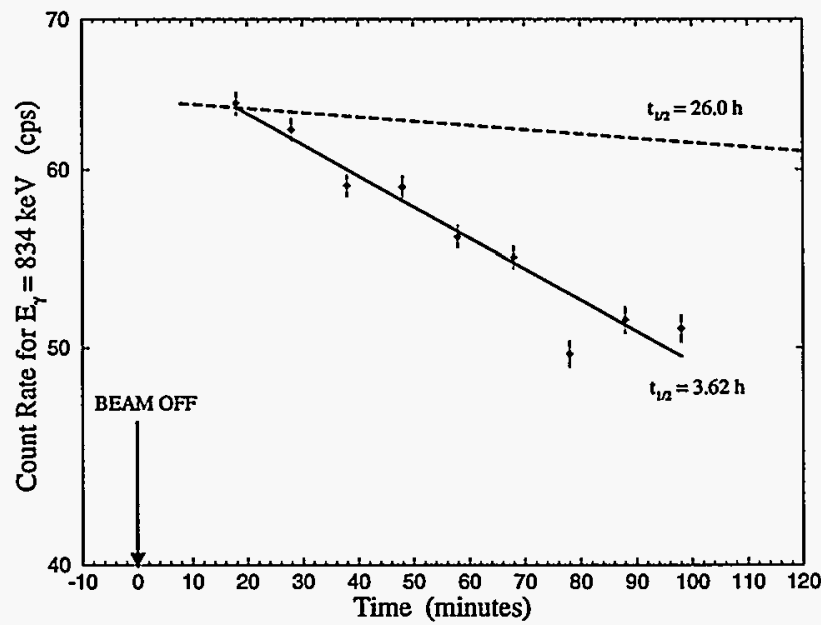

FIGURE 3. Release of ${ }^{72} \mathrm{As}$ after proton bombardment is stopped. The net count rate for the $834 \mathrm{keV} \gamma$-ray from ${ }^{72} \mathrm{As}$ is plotted versus the time with the solid line being an exponential fit to the data. The dashed line represents the half-life of ${ }^{n}$ As. 


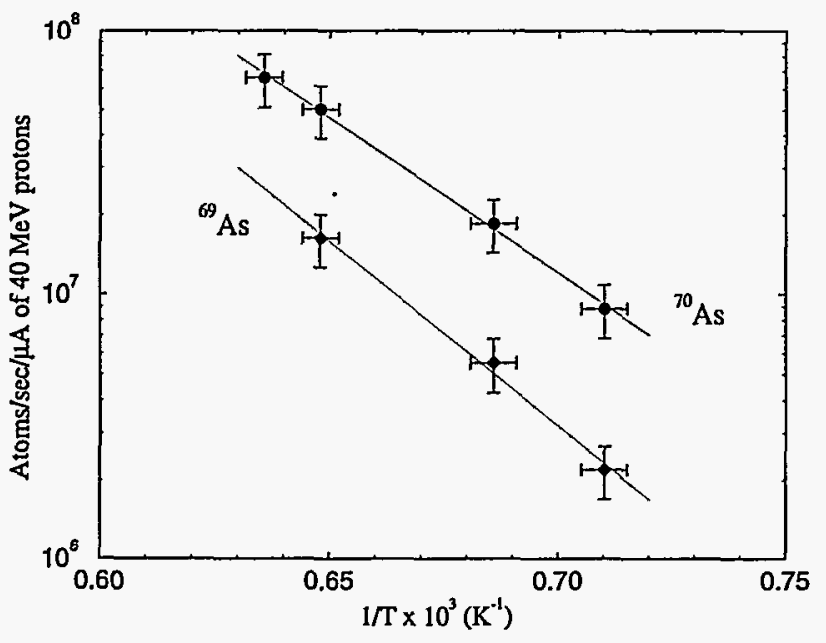

FIGURE 4. The normalized yield of ${ }^{69} \mathrm{As}$ and ${ }^{70} \mathrm{As}$ as a function of the inverse target temperature. The lines are exponential fits to the data. The counts are corrected for detector efficiency and branching ratio and are normalized to a proton beam intensity of $1 \mu \mathrm{A}$ on a ${ }^{70} \mathrm{Ge}$ target.

activity is built up in the target to enable such a measurement. The proton beam is stopped and the yield of ions released from the source is monitored as a function of time. This is shown in Fig. 3 for ${ }^{72}$ As. Since the radioactive half-life in this case is much longer than the apparent hold-up time, we say that the hold-up time is $3.6 \pm 0.3$ hours at $1300^{\circ} \mathrm{C}$.

Target temperature is an important parameter for any target/ion source. Figure 4 shows the equilibrium yield for ${ }^{69} \mathrm{As}$ and ${ }^{70} \mathrm{As}$ as a function of the inverse of the target temperature. The data show an exponential increase in the yield with increasing temperature and indicate that the target can be operated at much higher temperatures. The ion source efficiency was constant over the range of the data shown. The data in Fig. 4 are corrected for radioactive decay, detector efficiency and branching ratio and are normalized to $1 \mu \mathrm{A}$ of protons on an enriched ${ }^{70} \mathrm{Ge}$ target.

\section{Off-Line Fluorine Release Measurements}

For some time refractory oxides have been explored as a promising category of target materials for production of radioactive fluorine beams. The most encouraging results so far have been obtained with fibrous $\mathrm{Al}_{2} \mathrm{O}_{3}$. The material (8) consists of $3 \mu \mathrm{m}$ fibers of $\mathrm{Al}_{2} \mathrm{O}_{3}$ with a $\mathrm{SiO}_{2}$ binder ( $2 \%$ by weight) and a density of $0.12 \mathrm{~g} / \mathrm{cm}^{3}$. This $\mathrm{Al}_{2} \mathrm{O}_{3}$ was tested in an activation and off-line release measurement to determine the fluorine release efficiency. The material was irradiated with a low-intensity proton beam, which produced radioactive fluorine from the ${ }^{16} \mathrm{O}(\mathrm{d}, \mathrm{n})^{17} \mathrm{~F}$ and ${ }^{18} \mathrm{O}(\mathrm{p}, \mathrm{n})^{18} \mathrm{~F}$ reactions. The activity in the target was measured with a high-purity germanium detector to determine the quantity of ${ }^{18} \mathrm{~F}$ in the target. The $\mathrm{Al}_{2} \mathrm{O}_{3}$ target was then heated in a vacuum oven, and the

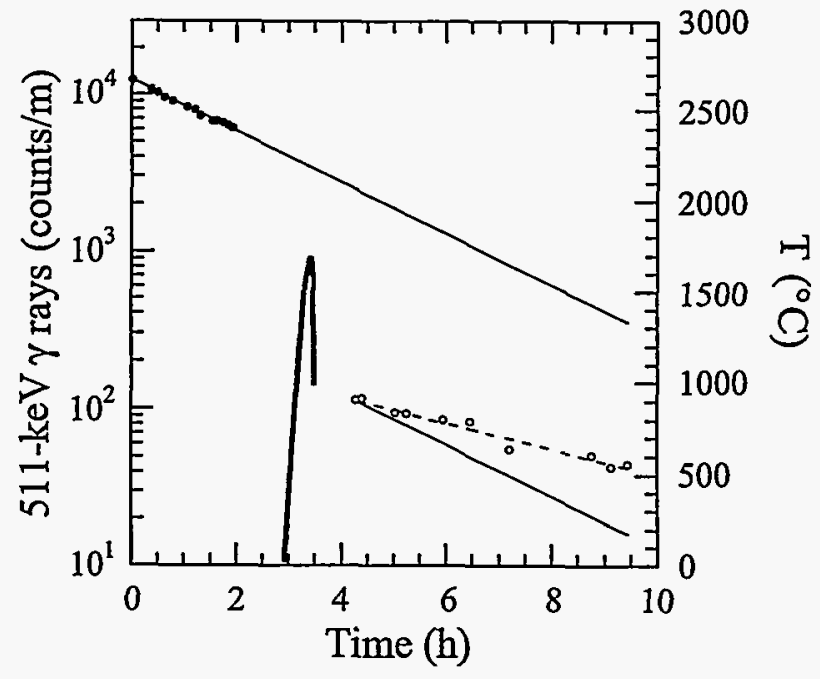

FIGURE 5. Activation and release measurement on fibrous $\mathrm{Al}_{2} \mathrm{O}_{3}$. The filled circles were measured prior to heating, and the open circles measured after heating. The heavy line is the temperature of the target during heating. The thin solid lines show the expected activity for $110 \mathrm{~m}$ half-life. The dashed line is an exponential fit to the data after heating which gives a half-life of $3.6 \mathrm{~h}$.

${ }^{18} \mathrm{~F}$ activity was measured again to determine the fractional release. Activation and release measurements performed with $\mathrm{Al}_{2} \mathrm{O}_{3}$ in a crystalline form $\left(\rho=3.7 \mathrm{~g} / \mathrm{cm}^{3}\right)$ showed no significant release. However, measurements performed with the fibrous $\mathrm{Al}_{2} \mathrm{O}_{3}$ showed near complete release for temperatures greater than $1400{ }^{\circ} \mathrm{C}$. The only radiation emitted by the decay of ${ }^{18} \mathrm{~F}$ is a $511-\mathrm{keV}$ gamma ray, so the number of $511-\mathrm{keV}$ gamma rays was measured as a function of time to determine the half-life of the activity.

The results of one measurement in which the fibrous $\mathrm{Al}_{2} \mathrm{O}_{3}$ was heated to a maximum temperature of 1700 ${ }^{\circ} \mathrm{C}$ is shown in Fig. 5. The activity measured before heating is in agreement with the known 110 minute half-life of ${ }^{18} \mathrm{~F}$. Following heating in the vacuum oven, only a few percent of the expected activity was observed to remain in the target material. Furthermore, the half-life of the remaining activity was found to be $3.6 \mathrm{~h}$. This activity is not from the decay of ${ }^{18} \mathrm{~F}$, but probably from the decay of an isotope produced by reactions on a contaminant in the $\mathrm{Al}_{2} \mathrm{O}_{3}$. We conclude that greater than $95 \%$ of the ${ }^{18} \mathrm{~F}$ is released after heating to $1700{ }^{\circ} \mathrm{C}$. Subsequent tests showed similar results with releases in excess of $80 \%$ for targets heated to $\mathrm{T}>1400^{\circ} \mathrm{C}$. For targets heated to $\mathrm{T}<1200$ ${ }^{\circ} \mathrm{C}$, no significant release was measured.

\section{On-Line Fluorine Experiments}

The performance of a similar ion source for the production of ${ }^{17.18} \mathrm{~F}$ was also tested. The only changes in the target/ion source from that described above are in the target holder and target material. The target material was the $\mathrm{Al}_{2} \mathrm{O}_{3}$ fibers and the target holder was 


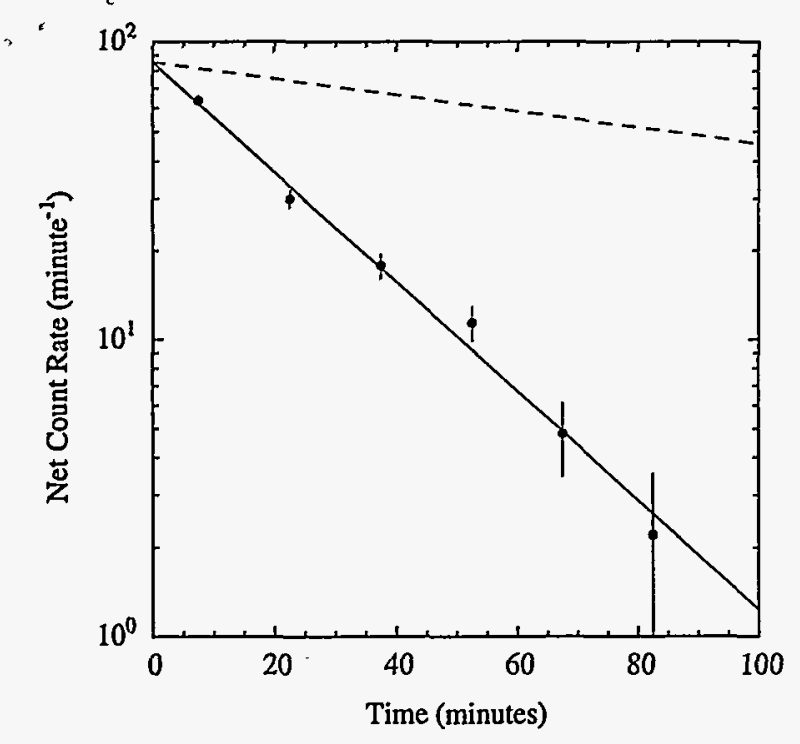

FIGURE 6. Release of $\mathrm{Al}^{18} \mathrm{~F}$ after proton bombardment is stopped. The net count rate for the annihilation radiation is plotted versus the time with the solid line being an exponential fit to the data. The dashed line represents the half-life of ${ }^{18} \mathrm{~F}$.

made of tantalum and welded to the transfer tube. The reactions used were ${ }^{16} \mathrm{O}(\mathrm{d}, \mathrm{n}){ }^{17} \mathrm{~F}\left(\mathrm{t}_{2}=64.5 \mathrm{~s}\right)$ and ${ }^{18} \mathrm{O}(\mathrm{p}, \mathrm{n}){ }^{18} \mathrm{~F}\left(\mathrm{t}_{\mathrm{r}}=110 \mathrm{~m}\right)$. Because of the extreme reactivity of atomic fluorine, the fluorine isotopes are transported in molecular form with $88 \%$ of the observed radioactive fluorine found in mass 44 (45) corresponding to $\mathrm{Al}^{17} \mathrm{~F}\left(\mathrm{Al}^{18} \mathrm{~F}\right)$. This is based on measurements of emitted $\gamma$-rays at other masses which could correspond to the following molecules (\% yield): $F(3), H F(2)$ and $\mathrm{SiF}(7)$. In addition, the following masses (molecules) were checked and negligible amounts of radioactive fluorine were observed: $28(\mathrm{BeF}), 42(\mathrm{NaF}), 47\left(\mathrm{BeF}_{2}\right)$, $58(\mathrm{KF})$ and $62(\mathrm{AlOF})$. At a target temperature of $1470^{\circ}$ $\mathrm{C}$ the efficiency of this source for $\mathrm{Al}^{17} \mathrm{~F} 0.0052 \pm$ $0.0008 \%$, and the efficiency for $\mathrm{Al}^{18} \mathrm{~F}$ was $0.06 \pm 0.02 \%$. The production rates were calculated from the measured cross sections (9) and tabulated stopping powers (10). The uncertainty in the efficiency is primarily due to the estimated uncertainty in the proton beam current on the target. The hold-up time was also measured at $1470^{\circ} \mathrm{C}$ using the longer lived $18 \mathrm{~F}$ isotope. The results of this measurement are shown in Fig. 6. By fitting the activity with an exponential, the hold-up time was determined to be $16.4 \pm 0.8$ minutes. We are currently exploring the effects of source parameters, such as temperature and surface passivation, on efficiencies and hold-up times.

\section{ACKNOWLEDGMENTS}

The authors wish to acknowledge the contribution of G. D. Alton who suggested and obtained the $\mathrm{Al}_{2} \mathrm{O}_{3}$ fiber material. We also appreciate the many helpful discussions with J. R. Beene, S. Ichikawa, H. Ravn, S. Sundell, W. L. Talbert and R. F. Welton. The technical drawings were made by G. D. Mills and C. A. Reed. Operations, upgrades and maintenance of the separator were ably performed by A. H. Poland.

Oak Ridge Institute for Science and Education is managed by Oak Ridge Associated Universities for the U.S. Department of Energy under contract number DEAC05-76OR00033. Oak Ridge National Laboratory is managed by Lockheed Martin Energy Research Corp. for the U.S. Department of Energy under contract number DE-AC05-96OR22464.

\section{REFERENCES}

$\dagger$ Also Physics Department, Vanderbilt University, Nashville, TN 37235, USA.

‡ Present address: Zur Steinhelle 31, Dertingen, Germany.

1. Carter, H. K., Mantica, P. F., Kormicki, J., Reed, C. A., Poland, A. H., Croft, W. L., and Zganjar, E. F., "UNISOR Separator Upgrade", Physics Div. Prog. Rpt. ORNL-6842, Martin Marietta Energy Systems, Inc. Oak Ridge National Laboratory, September 30, 1994.

2 Carter, H. K., Kormicki, J., Breitenbach, J., Ichikawa, S., Mantica, P. F., Alton, G. D., and Dellwo, J., "On-Line Ion Source/Target Release Time and Efficiency Experiments", Physics Div. Prog. Rpt. ORNL-6842, Martin Marietta Energy Systems, Inc. Oak Ridge National Laboratory, September 30, 1994.

3. Kirchner, R., Nucl. Instr. and Meth. in Phys. Res. B70, 186-199 (1992).

4. Alton, G. D., Dellwo, J., Murray S. N., and Reed. C. A., "Target Ion Source Development", and following articles, Physics Div. Prog. Rpt. ORNL-6842, Martin Marietta Energy Systems, Inc. Oak Ridge National Laboratory, September 30, 1994.

5. Ravn, H. L., Nucl. Instr. and Meth. in Phys. Res. B70, 107-117 (1992).

6 Kirchner, R., Nucl. Instr. and Meth. in Phys. Res. B26, 204-218 (1987).

7. Gomez del Campo, J., private communication using a statistical model code, LILITA, 1996.

8. Alcen@, alumina fiber supplied by RATH Performance Fibers, Wilmington, DE, USA.

9. Gruhle, W., Schmidt, W., and Burgmer, W., Nucl. Phys. A186, 257-263 (1972)

10. Anderson, H. H., and Ziegler, J. F., Hydrogen Stopping Powers and Ranges in All Elements, New York: Pergamon Press, 1977. 